\title{
Water: From Pollution to Purification
}

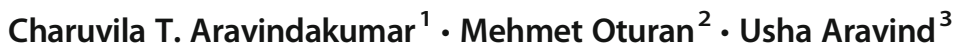

Received: 29 April 2018 / Accepted: 17 May 2018 / Published online: 6 June 2018

(C) Springer-Verlag GmbH Germany, part of Springer Nature 2018

This special issue WPP (Water: From Pollution to Purification) of Environmental Science and Pollution Research presents selected papers presented at the second International conference on Water: From Pollution to Purification (ICW2016) conducted during Dec.12-15, 2016, in Kottayam (Kerala, India) hosted jointly by Inter University Instrumentation Centre (IUIC), the School of Environmental Sciences, and the Advanced Centre of Environmental Studies and Sustainable Development: An Inter University Centre (ACESSD), Mahatma Gandhi University, Kottayam along with the Centre for Environment Education and Technology (CEET), Kottayam.

Water pollution and potable water scarcity are two issues which have been in the limelight for so many decades. Rapid industrialization, demographic explosion, and unscientific water resource management are the major reasons for the situation. A wide array of pollutants from nutrients (nitrates and phosphates) to contaminants of emerging concern is affecting the quality of global water resources. All these issues are of particular concern in India too. In this context, water pollution and treatment technologies are two important areas of interest. The involvement of several sophisticated equipments in recent years helped to detect trace amount of pesticides, pharmaceuticals and personal care products, heavy metals, and other emerging pollutants in water bodies. A wide variety of water treatment technologies are also being developed. However, an economically viable as well as highly efficient water treatment technique for treating all the chemical water contaminants is still

Responsible editor: Philippe Garrigues

Charuvila T. Aravindakumar

cta@mgu.ac.in

1 School of Environmental Sciences, Mahatma Gandhi University, Kottayam 686560, Kerala, India

2 Laboratoire Géomatériaux et Environnement (LGE), Université Paris-Est, EA 4508, UPEM, 77454 Marne-la-Vallée, France

3 Advanced Centre of Environmental Studies and Sustainable Development, Mahatma Gandhi University,

Kottayam 686560, Kerala, India under intense research. On the other hand, it is really a paradox that when there is a cry for cheaper water purification technologies, a high price is being given to tackle water borne diseases. The main objective of the conference was, therefore, to bring together experts in diversified areas of environmental science and technology. Another component of this conference was a discussion on environmental awareness and education. The participants were from several countries. Indian participants are from mainly national research organizations and industrial R\&Ds and from central and state universities. ICW2016 thus connected researchers from chemistry, physics, engineering, environment, geology, and many more due to its interdisciplinary nature. The main focuses of the conference were fixed as,

- Agricultural, industrial, and domestic pollution of water

- Pollution from emerging pollutants (pesticides, pharmaceuticals and personal care products, nanoparticles, etc.)

- Pollution from industries (distilleries, tanneries, textiles, and paper industry)

- Heavy metal contamination

- Pollution from radioactive materials

- Physical treatments (membrane separation, adsorption, etc.)

- Chemical treatments (oxidation process, coagulation, precipitation, stabilization, etc.)

- Biological treatments (bioreactors, activated sludge process, etc.)

- Nanotechnology in water treatment

- Photocatalytic and other oxidation technologies

The conference was attended by nearly 250 participants from all over the world. It was enriched with 5 plenary talks, 26 invited talks, 25 short talks, 10 young investigators presentations, and 74 posters. The young investigator session was designed after a rigorous selection of invited papers from investigators below the age of 30 . The response from the participants and other connected scientists for manuscript submission to this special issue was very encouraging. Nearly 69 papers were submitted to this special issue and after a thorough review process, 27 papers were accepted. Eight 
manuscripts were rejected after peer review. Thierteen manuscripts were rejected after initial screening. Another 21 manuscripts were rejected for possible resubmission. Since the authors could not resubmit this on time, these manuscripts were not considered for inclusion. The accepted papers cover a wide range of research issues related to both pollution and purification/remediation of water. This covers specific monitoring of pollutants in water bodies, engineering aspects of potential pilot plants for water purification, various advanced material for water treatment, and oxidation technologies for the removal of organic pollutants from water.

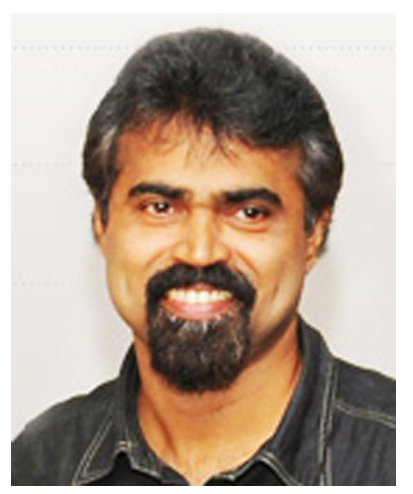

Charuvila T. Aravindakumar : Professor of School of Environmental Sciences and Dean of the Faculty of Environmental \& Atmospheric Sciences of Mahatma Gandhi University (MGU), Kottayam, India. He received $\mathrm{Ph} . \mathrm{D}$ in chemistry from the University of Pune (India) and later worked in several international laboratories such as Max-Planck-Institute for Radiation chemistry (Germany), Catholic University of Leuven (Belgium), and Free University, Amsterdam (Netherlands). He has over 25 years of post-graduate teaching and research experience after Ph.D. The main areas of research are Environmental Chemistry, Water purification technology, Air pollution, Radiation science, Photochemistry; polar research (Indian Polar Expedition), Environmental Education \& Governance. Fourteen Ph.Ds were awarded under his supervision in MGU. Over the past 25 years, he has collaborated with many national and international laboratories under various programs (in the USA, Germany, South Korea, Canada, France). He was a visiting professor at the University of Paris-Est-Marnela-Vallee in 2013 and 2015. He has set up a highly sophisticated analytical laboratory in MGU. He has completed nearly 10 major research projects with fundings from various national and international agencies, and 3 are ongoing (amount of support $>80$ million INR). He has over 75 journal publications and over 230 publications in conference proceedings.

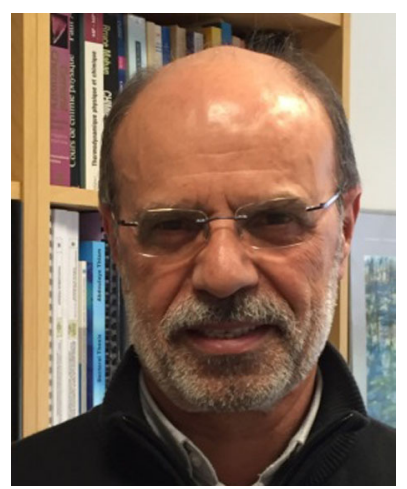

Mehmet A Oturan : Professor/ PhD supervisor, head of Geomaterials department at Paris-Est Marne-la-Vallée. His current research interest includes advanced oxidation processes (AOPs) and particularly electrochemical advanced oxidation processes (EAOPs), particularly electro-Fenton process (that he was inventor of carbon-felt cathode version), and their application to treatment of wastewater and soil remediation, including chemical kinetics and mechanisms of oxidation reactions induced by hydroxyl radical. He was a visiting scientist at Albert Einstein College, New York (1994); Wuhan University, China (2010, 2014-2017); Mahatma Gandhi University, KottayamKerala, India (2012), in the frame of the program ERUDITE; and Gabes University, Tunisia, during 2012-2018. He has supervised 42 $\mathrm{PhD}$ theses; has published more than $220 \mathrm{SCI}$ articles, 3 books, and 9 book chapters; and has presented about 60 invited conferences at scientific national/international congress and institutions. His current Web of Science h-index is 53 with more than 9000 citations (following web of science). He has been Associate Editor of the Journal of Environ. Eng. Monit. (2006-2010), and currently serves Sustain. Environ. Res., and Environ. Chem. Lett. as Associate Editor. He is member of Editorial Board of several scientific journals including Appl. Catal. B: Environ.

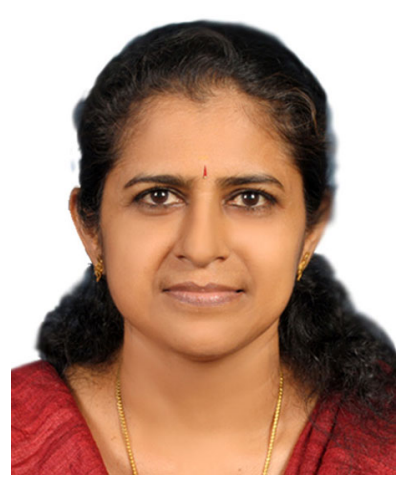

Usha Aravind : Research Coordinator at the Advanced Centre of Environmental Studies and Sustainable Development (ACESSD): An Inter University Centre of the Government of Kerala in the Mahatma Gandhi University Campus. She received her Ph.D in Chemistry from the Cochin University of Science \& Technology, Kochi, and postdoctoral research at the Catholic University of Leuven (Belgium) and Technical University of Eindhoven (The Netherlands). The research interest of Usha is in the creation of nano architecture of polysaccharides, proteins, polypeptides, polymers on membrane surfaces to enhance their separation ability for water pollutants (chemical and biological), trapping and killing of microbes from potable water, recycle and reuse of gray water, development of recyclable water filters, recovery of nutrients, their pathways, green technological routes for the removal of emerging contaminants, water sensors, probing the protein-pollutant (bisphenols, parabens, mercury) interaction (misfolding) based on biophysical studies. She is also involved in water literacy camps for school children, self-help groups and local authorities, sustainability of ponds, rivers and lakes in Kerala. She is the awardee of seven major projects. She has over 40 journal publications, a book chapter, and over 150 papers in conference proceedings. 